\title{
An efficient protocol to generate placental chorionic plate-derived mesenchymal stem cells with superior proliferative and immunomodulatory properties
}

Qilin Huang ${ }^{1,2+}$, Yi Yang $^{1,2+}$, Chen Luo ${ }^{1}$, Yi Wen ${ }^{1}$, Ruohong Liu', Shuai Li ${ }^{1}$, Tao Chen ${ }^{1}$, Hongyu Sun ${ }^{1 *}$ and Lijun Tang ${ }^{1,2^{*}}$ (D)

\begin{abstract}
Background: Placenta-derived MSCS (P-MSCs) represent a promising tool for cell-based therapeutic applications. However, the increasing demand for P-MSCs in clinical trials makes high quality and large number of P-MSCs mandatory. Here, we aim to develop an efficient protocol for P-MSC isolation and culture.

Methods: The modified explant culture (MEC) method by combining an initial mild enzymatic reaction with the subsequent explant culture was developed to simultaneously produce various P-MSCs from the different regions of the placenta in serum-free medium (SFM). Its isolation efficiencies, cell yield, and proliferative capacity were compared with the conventional explant culture (EC) method. Furthermore, we determined whether functional properties of P-MSCs are affected by the used tissue-harvesting sites in terms of their proliferation, migration, and the immunomodulatory effect on macrophage.

Results: The MEC method achieved higher yield and shorter time in primary cell confluence in SFM compared with the conventional method. The harvested cells possessed the MSC characteristics and demonstrated significantly stronger proliferation ability. Importantly, MSCs derived from chorionic plate (CP-MSCs) were found to exhibit superior properties to the other P-MSCs in proliferation and migration capacity, maintaining the fetal origin over serial passages. Notably, CP-MSCs show stronger ability in regulating macrophage polarization from M1 to M2.
\end{abstract}

Conclusion: Our study developed an efficient and high-yield technique to produce high-quality P-MSCs from the placenta, hence serving as an optimal source of MSCs for clinical application.

Keywords: Mesenchymal stem cells, Isolation, The modified explant culture method, Chorionic plate-derived MSCs, Macrophage

\section{Background}

Mesenchymal stem cells (MSCs) are considered as potential therapeutic tools for clinical application due to their beneficial characteristics including high self-renewal and multipotent differentiation [1], low immunogenicity, and immunomodulatory abilities $[2,3]$. Accumulating evidence from clinical trials indicates that MSCs exert

\footnotetext{
*Correspondence: shongyu2008@163.com; tanglj2016@163.com

${ }^{+}$Qilin Huang and Yi Yang contributed equally to this work.

'Department of General Surgery \& Pancreatic Injury and Repair Key Laboratory of Sichuan Province, The General Hospital of Western Theater Command (Chengdu Military General Hospital), Chengdu 610083, China
} Full list of author information is available at the end of the article therapeutic effects in numerous diseases such as graft versus host disease (GVHD) [4], liver failure [5], acute myocardial infarction [6], rheumatoid arthritis [7], and liver cirrhosis [8]. Originally, MSCs were isolated from the bone marrow (BM). However, BM is not an ideal source of MSCs in view of the low cell numbers, the invasive harvesting procedure, and the reduced proliferation capacity by age [9-11]. Therefore, it is necessary to find out alternative MSC sources for clinical applications.

Perinatal tissues like the placenta and umbilical cord are promising MSC sources because they possess several advantages such as easy accessibility, noninvasive procedures,

(c) The Author(s). 2019 Open Access This article is distributed under the terms of the Creative Commons Attribution 4.0 International License (http://creativecommons.org/licenses/by/4.0/), which permits unrestricted use, distribution, and 
and minimal ethical constraints. Compared to MSCs derived from adult $\mathrm{BM}$ or adipose tissues, placenta-derived MSCs (P-MSCs) and umbilical cord-derived MSCs (UCMSCs) are generally considered as fetal cells with superior proliferation ability [12], stronger immunomodulatory [13], and lower immunogenicity [14]. Moreover, a recent study found that P-MSCs possess better immunoregulatory properties compared to UC-MSCs [15]. Hence, it seems that the placenta is the better choice for obtaining MSCs. Currently, various kinds of P-MSCs have been successively isolated from different anatomical regions of the placenta, including chorionic plate-derived MSCs (CP-MSCs), chorionic villiderived MSCs (CV-MSCs), amniotic membrane-derived MSCs (AM-MSCs), and decidua-derived MSCs (D-MSCs). However, there is no consensus on the quality of the current cultured P-MSCs, thereby making standardization production of P-MSCs difficult. As reported in the literature, the current cultured P-MSCs are usually confounded by maternal cell contamination [16-18]. The reason behind this phenomenon is complicated, like the variation in MSCs obtained from different regions of the placenta, culture system, and so on. Therefore, it is mandatory to define the key parameters to obtain high-quality MSCs like as pure fetal P-MSCs for clinical trials.

As P-MSCs are gaining more and more attention in clinical trials, there are increasing concerns regarding the isolation and culture. However, no standard isolation methods for P-MSCs are available. Currently, the main methods for isolating P-MSCs are the enzymatic method and the explant culture (EC) method. In the enzymatic method, the tissue block is digested with proteolytic enzymes, and the cell suspension obtained is cultured. However, some studies have demonstrated that the enzymatic method affects the biological characteristics of MSCs such as proliferative capacity and reduces cell viability due to prolonged digestion $[19,20]$. Although the MSCs obtained by EC have better biological functions, it takes longer time to reach cell confluence due to the slower migration of cells from the tissue block. Therefore, it is necessary to develop a simple and efficient method to obtain larger numbers of P-MSCs in a shorter time.

In this context, our study aims to develop and optimize an efficient isolation and culture system for harvesting large numbers of pure fetal P-MSCs with superior properties. The modified explant culture (MEC) method by combining an initial mild enzymatic reaction with the subsequent explant culture was developed to simultaneously produce various P-MSCs from the different regions of the placenta in serum-free medium (SFM). Its isolation efficiencies, cell yield, and proliferative capacity were compared with the conventional explant culture (EC) method. Moreover, the properties of various P-MSCs were also compared in terms of their origin, proliferation, migration, and the immunomodulatory effect on macrophage.

\section{Methods}

\section{Sample collection}

Approval of the Institutional Ethics Committee of the General Hospital of Western Theater Command was obtained for the sample collection, processing, and other experimental procedures before initiating this experiment. Human placentas of uncomplicated, elective cesarean deliveries at term were collected after obtaining written informed consent from the mother. And only pregnancies with a male fetus were chosen.

\section{Anatomical dissection approach}

MSCs were isolated as described [16, 21-23] but with modifications to select placental tissue based on anatomical structure (see Fig. 1).

\section{Umbilical cord-derived (UC)-MSCs}

The umbilical cord tissue was cut and then placed in a sterile petri dish with wash of phosphate-buffered saline (PBS) containing 1\% penicillin-streptomycin (Gibco, USA) to remove the blood on it. Finally, the umbilical cord tissue was minced.

\section{Chorionic plate-derived (CP)-MSCS}

Upon removal of the amniotic membrane from the fetal surface of the placenta, the chorionic plate from the region closest to the umbilical cord was dissected, then washed and minced.

\section{Chorionic villi-derived (CV)-MSCs}

Approximately $0.5 \mathrm{~cm}$ deep into the placental tissue was dissected from chorionic villi from the region closest to the umbilical cord and $\geq 1 \mathrm{~cm}$ away from the maternal side of the placenta (decidua). Chorionic villi tissue was placed in a sterile culture dish, washed, minced, digested, and inoculated to a T75 culture flask.

\section{Decidua-derived (D)-MSCs}

After the maternal side of the placenta was faced upward, decidua tissue was cut from the center of the placenta with the cutting depth controlled within $0.5 \mathrm{~cm}$ by a sterile anatomical instrument. The decidua tissue was placed in a sterile culture dish, then washed, minced, digested, and inoculated to a T75 culture flask.

\section{MSC serum-free culture system}

MSCs were isolated as early as possible after delivery of the placenta, commonly within 3-6 h. According to the placental anatomy, cut the appropriate amount of tissue blocks from the corresponding parts of the placenta and umbilical cord, and then transfer the tissue blocks to a sterile culture dish with wash of PBS containing $1 \%$ penicillinstreptomycin. The tissue block was cut with a sterile tissue scissors $(2-3 \mathrm{~mm}$ in diameter) and then divided into two 


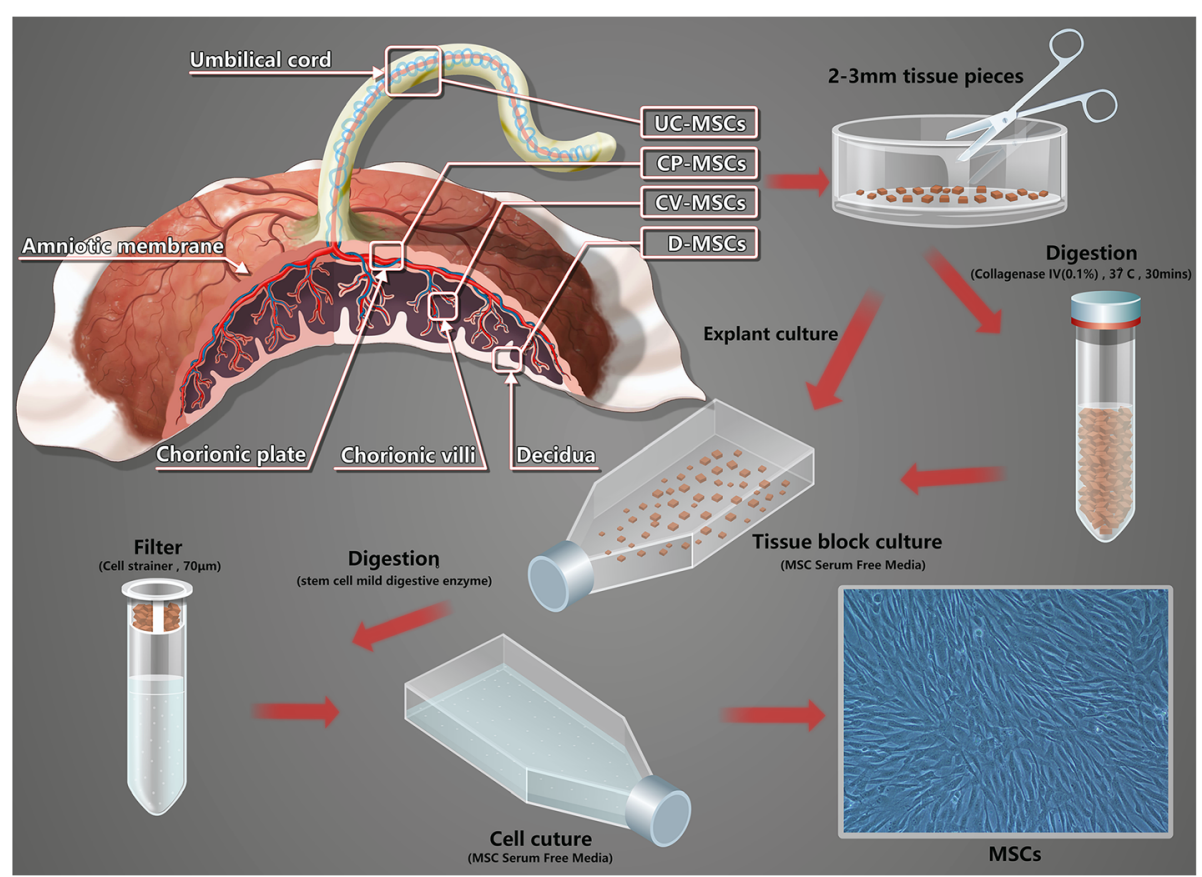

Fig. 1 Schematic diagram of the isolation of MSCs from the human umbilical cord and placenta. MSCs were isolated by MEC and EC from the different regions of the placenta and umbilical cord. Modified explant culture (MEC): the shredded tissue block was transferred to a centrifuge tube and incubated with digest media $\left(0.1 \%\right.$ collagenase IV) for $30 \mathrm{~min}$, at $37^{\circ} \mathrm{C}$ with gentle rocking. After digestion, tissue block was washed three times with PBS, centrifuged $\left(300 \mathrm{~g}, 5 \mathrm{~min}, 4^{\circ} \mathrm{C}\right)$, resuspended with MSC Serum Free Media, then transferred to a T75 culture flask and cultured. Explant culture (EC): the shredded tissue block was mixed with MSC Serum Free Media, and then transferred to a T75 culture flask and cultured

portions, one for MEC and the other for EC. (A) Modified explant culture (MEC): the shredded tissue block was transferred to a centrifuge tube, and then incubated with digest media (serum-free Dulbecco's modified Eagle medium (DMEM; Hyclone, USA) containing $0.1 \%$ collagenase IV (Sigma, USA)) for $30 \mathrm{~min}$, at $37^{\circ} \mathrm{C}$ with gentle rocking. Freshly prepared digest media was incubated at least a 1:1 ratio with the tissue block. After digestion, tissue block was washed three times with PBS and then centrifuged (300g, 5 min, $4{ }^{\circ} \mathrm{C}$ ). The pellet was resuspended with MSC Serum Free Media (Yocon, China), and then transferred to a T75 culture flask and cultured at $37^{\circ} \mathrm{C}$ in a humidified atmosphere with 5\% CO2. (B) Explant culture (EC): the shredded tissue block was mixed with MSC Serum Free Media, and then transferred to a T75 culture flask and cultured at $37^{\circ} \mathrm{C}$ in a humidified atmosphere with $5 \% \mathrm{CO} 2$. (Note: do not move the T75 culture flask for the first 3 days). From the fourth day, the state of cell growth was observed every 2 days, and subculture was carried out at a density of 8000 / $\mathrm{cm}^{2}$ when primary cell confluence reaching approximately $80 \%$. Detailed method of MSC subculture is seen in Additional file 1.

\section{Macrophage and MSC noncontact co-culture}

Macrophages were isolated as described earlier, and the detailed method is seen in Additional file 1 [24]. First, macrophages were treated with $1 \mu \mathrm{g} / \mathrm{ml}$ lipopolysaccharide (LPS; sigma, USA) for $24 \mathrm{~h}$ to induce polarization to M1, and then macrophages and MSCs were co-cultured at 5:1 through transwell chamber $(0.4-\mu \mathrm{m}$ pore size; Corning, USA) for $24 \mathrm{~h}$, where macrophages and MSCs were located in the lower and upper compartment of the chamber respectively. The cell culture supernatant was collected to measure the concentration of inflammatory factor by enzyme-linked immunosorbent assay (ELISA). Macrophages were harvested for flow cytometry and RNA extraction.

\section{Enzyme-linked immunosorbent assay}

The assay kits for measurements of interleukin (IL)-10, prostaglandin E2 (PGE2), and tumor necrosis factor (TNF) $\alpha$ were purchased from Shanghai Jianglai Biotech, China. Detailed operating steps are according to the products' instructions. Each sample was measured in triplicate.

\section{RNA extraction and real-time quantitative PCR}

Total RNA was extracted using Trizol reagent (Invitrogen Inc., USA), according to the products' instructions. The RNA was quantified by measuring the absorbance at $260 \mathrm{~nm}$ and $280 \mathrm{~nm}$ using a spectrophotometer (NanoDrop Technologies, USA). Real-time quantitative PCR (qRT-PCR) was performed with a CFX96 Real- 
Time PCR Detection System (Bio-Rad, USA) using one step SYBR PrimeScript RT-PCR Kit (TaKaRa, Japan). Each sample was performed in triplicate. The primers used are shown in Additional file 1: Table S1.

\section{Flow cytometry analysis}

Phenotype of MSCs was analyzed using the following antibodies: fluorescein isothiocyanate (FITC)-conjugated CD73, CD90, CD105, CD44, CD14, CD34, and HLA-DR; phycoerythrin (PE)-conjugated CD106, CD166, CD45, and CD19; and allophycocyanin (APC)-conjugated CD54 (Biolegend, USA). Polarized phenotype of macrophages was analyzed using the following antibodies: FITC-conjugated CD163 (Bio-Rad, USA), PE-conjugated CD86 (BD Biosciences, USA), and Alexa-Flour647-conjugated CD68 (Bio-Rad, USA). Non-specific isotype-matched antibodies served as controls. The cells were analyzed using a flow cytometry instrument (BD CantoII, USA), and the data were analyzed using FlowJo V10 (Tree Star Inc., USA).

\section{Trilineage differentiation assay}

Mesenchymal stem cell adipogenic, osteogenic, or chondrogenic induction medium (Cyagen, Suzhou, China) was used to induce differentiation of MSCs into adipocytes, osteoblasts, and chondrocytes, respectively. To assess adipogenic differentiation, lipid droplets of differentiated cells were stained using Oil Red O. To assess osteogenic differentiation, cells were stained with Alizarin Red S. To assess chondrogenic differentiation, cells were stained with Alcian blue.

\section{$\mathrm{XY}$ chromosome fluorescence in situ hybridization (XY- FISH)}

MSCs derived from the placental chorionic plate, chorionic villi, decidua, and umbilical cord were used for FISH assays to identify the ratio of fetal-derived MSCs to maternal-derived MSCs. FISH was carried out using FISH CEP probe of human chromosome X-Green/Y-Orange (GeneCopoeia Inc., USA) according to the manufacturer's instructions. Laser confocal microscopy (Nikon A1R+, Japan) was used for image acquisition.

\section{Growth kinetics analysis}

The proliferation of MSCs from P3 to P9 was assessed. All MSCs were inoculated on a six-well culture plate at a density of $8 \times 10^{4}$ cells/well, and the cells were counted until they reached $100 \%$ confluence. The population doubling time (PDT) was calculated using the following formula: $\mathrm{PDT}=(\mathrm{CT} \times \ln 2) / \ln \left(N_{\mathrm{f}} / N_{\mathrm{i}}\right)$, where CT is the cell culture time, $N_{\mathrm{i}}$ is the initial number of cells, and $N_{\mathrm{f}}$ is the final number of cells [25].

\section{Cell Counting Kit-8 (CCK-8) assay}

The proliferation of MSCs (P4) was determined using the Cell Counting Kit-8 (CCK-8, Dojindo Molecular
Technology, Japan). MSCs were adjusted to a concentration of $2 \times 10^{4}$ cells $/ \mathrm{ml}$ with MSC Serum-Free Medium, and then $100 \mu \mathrm{l}$ of it was added to each well of the 96well culture plate. After incubation for the first $24 \mathrm{~h}$, the viable cell number was then tested every $24 \mathrm{~h}$ for seven consecutive days. Before the test, $10 \mu \mathrm{l} \mathrm{CCK-8} \mathrm{reagent}$ was added to each well, and the plates were incubated at $37^{\circ} \mathrm{C}$ for $2 \mathrm{~h}$. To determine the number of viable MSCs, the optical density value at $450 \mathrm{~nm}$ was detected with a spectrophotometer (Multiskan GO, Thermo Scientific).

\section{Cell cycle analysis}

Cell cycle analysis of MSCs was carried out at P4. The cell concentration was adjusted to $1 \times 10^{6} \mathrm{cells} / \mathrm{ml}$. After centrifugation, the supernatant was removed and $500 \mu \mathrm{l}$ $70 \%$ cold ethanol was added to the cells for fixation $(2 \mathrm{~h}$ to overnight), stored at $4{ }^{\circ} \mathrm{C}$. Five hundred microliters of $\mathrm{PI} / \mathrm{RNase} \mathrm{A}$ staining solution was added to the cells after they have been washed with PBS and centrifuged to remove fixing solution. Undergoing incubation for $30 \mathrm{~min}$ at $4{ }^{\circ} \mathrm{C}$, the cells were then analyzed using a flow cytometry instrument (BD CantoII, USA) and the data were analyzed using FlowJo V10 (Tree Star Inc., USA).

\section{Scratch test}

Before inoculation of cells, use a marker pen to draw three horizontal lines behind the six-well culture plate at intervals of $0.5 \mathrm{~cm}$. Cells $\left(4 \times 10^{5} /\right.$ well $)$ were added to each well, and the plates were incubated at $37^{\circ} \mathrm{C}$. When the cells reached $100 \%$ confluence, $200-\mu$ lip was used to draw three scratches perpendicular to the back horizontal line. After being washed by PBS and cultured in serum-free DMEM, cells were observed and photographed at $0 \mathrm{~h}, 6 \mathrm{~h}, 12 \mathrm{~h}$, and $24 \mathrm{~h}$. The wound size subsequently was measured and analyzed using ImageJ software (Rawak Software, Inc. Germany).

\section{Transwell migration assay}

Besides the scratch test, migration ability of MSCs was also tested by transwell chambers (24-well culture plate, $8-\mu \mathrm{m}$ pore size). MSCs were adjusted to a concentration of $2 \times 10^{5}$ cells $/ \mathrm{ml}$ with MSC Serum-Free Medium, and then $100-\mu \mathrm{l}$ cell suspension was added to the upper chamber of the migration well. To the contrary, MSC Serum-Free Medium and chemokine stromal-derived factor-1 (SDF-1, $100 \mathrm{ng} / \mathrm{ml}$, Millipore) were loaded into the lower chamber. Then, the cells were cultured at $37^{\circ} \mathrm{C}$ in a $5 \% \mathrm{CO} 2$ incubator, and the plates were taken out at $6 \mathrm{~h}, 12 \mathrm{~h}$, and $24 \mathrm{~h}$ for observation. First, the cells on the filter were removed with a cotton swab, then fixed with $4 \%$ paraformaldehyde for $30 \mathrm{~min}$, and finally stained with crystal violet (Beyotime, Haimen, China) for $20 \mathrm{~min}$. Cells in five random separate microscope fields 
were counted by ImageJ software (Rawak Software, Inc. Germany).

\section{Statistical analysis}

Statistics as well as graphical representations were performed using GraphPad Prism ${ }^{\text {Tx }} 7.0$ (GraphPad Software Inc., USA). Parametric data are expressed as the means \pm SD. Unless otherwise noticed, differences between the two experimental groups were applied using an unpaired twotailed Student's $t$ test. For comparison of more than three groups, one-way analysis of variance (ANOVA) was applied, and nonparametrically distributed variables were compared by the Mann-Whitney $U$ test using SPSS 18.0 (SPSS Inc., USA). Results were considered statistically significant with $p$ values: ${ }^{*} p<0.05,{ }^{* * *} p<0.01$, and ${ }^{* * * *} p<0.001$.

\section{Results}

Establishment of an effective isolation and culture system for MSCs

To investigate whether the MEC method is an efficient and suitable method to isolate MSCs from perinatal tissues in SFM, we compared its efficiencies and cell yield with that using the EC method. CP-MSCs and UCMSCs were taken as representative examples for the comparison of MSC isolate methods. Additionally, cell quality and proliferation were also evaluated.

\section{MEC achieves a higher efficiency to isolate MSCs from perinatal tissues in SFM}

We simultaneously isolated MSCs from the CP and UC tissue by the MEC and EC methods. At day 4, rod-like and irregularly shaped cells were observed to migrate from the CP and UC tissue in the MEC group while no cells were detected in the EC group. Notably, cells reached approximately $80 \%$ confluence in the $\mathrm{CP}$ tissue at day 8 and in the UC tissue at day 10 in the MEC group. In contrast, only a few migrated cells were observed at day 8 and cell confluence was detected at days 13 and 16 for the $\mathrm{CP}$ and $\mathrm{UC}$ tissue respectively in the EC group (Fig. 2a). As shown in Fig. 2c, primary cell confluence took significantly less time with the MEC method than with the EC method. Importantly, the MEC method yielded significantly more cells in comparison with the EC method (Fig. 2d). Overall, these data suggest that the MEC method could be used as an efficient technique to isolate MSCs from perinatal tissues and harvest a higher yield.

\section{MSCs obtained by MEC exhibited superior proliferative properties}

To determine whether our developed MEC method has any influence on MSC growth, we compared the proliferation rate of MSCs isolated using MEC than that using EC by population doubling time (PDT), CCK- 8 assay, and cell cycle analysis. PDT of MSCs obtained by MEC was significantly shorter than that of MSCs obtained by the EC method (Fig. 2g, h). The CCK-8 assay also showed that MSCs obtained by the MEC method had stronger proliferative activity (Fig. 2i, j). This result was further supported by the cell cycle analysis in which the MEC method had more cells in the dividing phase (Fig. 2b, e, f).

\section{Advantageous properties of the generated CP-MSCs using the new protocol}

To determine whether the biological properties of $\mathrm{P}$ MSCs using MEC is related to the anatomical sites of the placenta, we thus simultaneously isolated from the different regions of the placenta using the new protocol, including CP-MSCs, CV-MSCs, and D-MSCs. Here, UC-MSCs were used as a control. The quality of these various PMSCs was assessed to verify their function properties.

\section{MSCs obtained by MEC meet the criteria of MSCs proposed by the ISCT}

To determine whether the isolated MSCs using MEC were truly MSCs, we identified the biological characteristics of all isolated MSCs by immunophenotypic analysis and trilineage differentiation assay.

Immunophenotypic analysis, regardless of differences in origin, of all MSCs exhibited a characteristic marker profile. MSCs were positive for CD73, CD90, CD105, CD44, and CD166 ( $\geq 95 \%)$ and negative for CD45, CD34, CD14, CD19, and HLA-DR $(\leq 2 \%)$ (Fig. 3a, Additional file 1 : Table S2). In vitro differentiation assay showed that all MSCs were able to differentiate into adipogenic, osteogenic, and chondrogenic lineages (Fig. 3b). The above data indicates that all MSCs meet the criteria of MSCs proposed by the International Society for Cellular Therapies (ISCT) [26].

\section{CP-MSCs are of fetal origin and superior to other P-MSCs in the origins}

To identify the ratio of fetal-derived MSCs to maternalderived MSCs, the isolated MSCs including CP-MSCs, CV-MSCs, D-MSCs, and UC-MSCs were used for XY chromosome fluorescence in situ hybridization (XYFISH) experiments.

As shown, the fetal-derived MSCs appear as one X chromosome (green) and one Y chromosome (red) while the maternal-derived MSCs appear as two X chromosomes (Fig. 4a-c). No maternal-derived MSCs were noted in CP-MSCs and UC-MSCs from P1 to P5. However, the proportion of maternal-derived MSCs was $18 \pm$ $7 \%, 13 \pm 6 \%$, and $9 \pm 4 \%$ in P1, P3, and P5 of CV-MSCs respectively and $65 \pm 15 \%, 54 \pm 11 \%, 48 \pm 10 \%$ respectively in P1, P3, and P5 of D-MSCs (Fig. 4d). In addition, we found that the proportion of maternal-derived MSCs in CV-MSCs and D-MSCs gradually decreased with the 


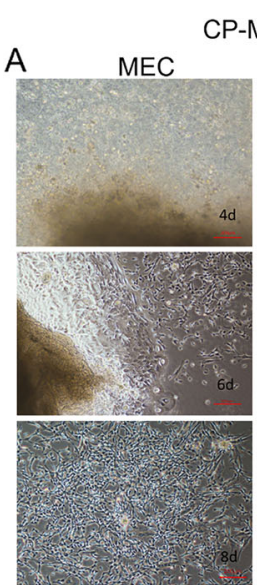

CP-MSCs
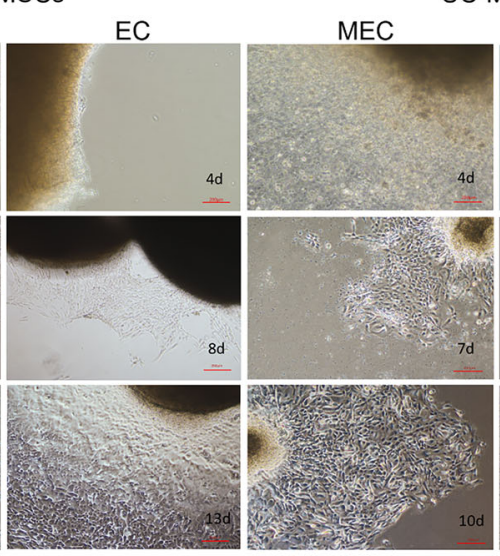

UC-MSCs
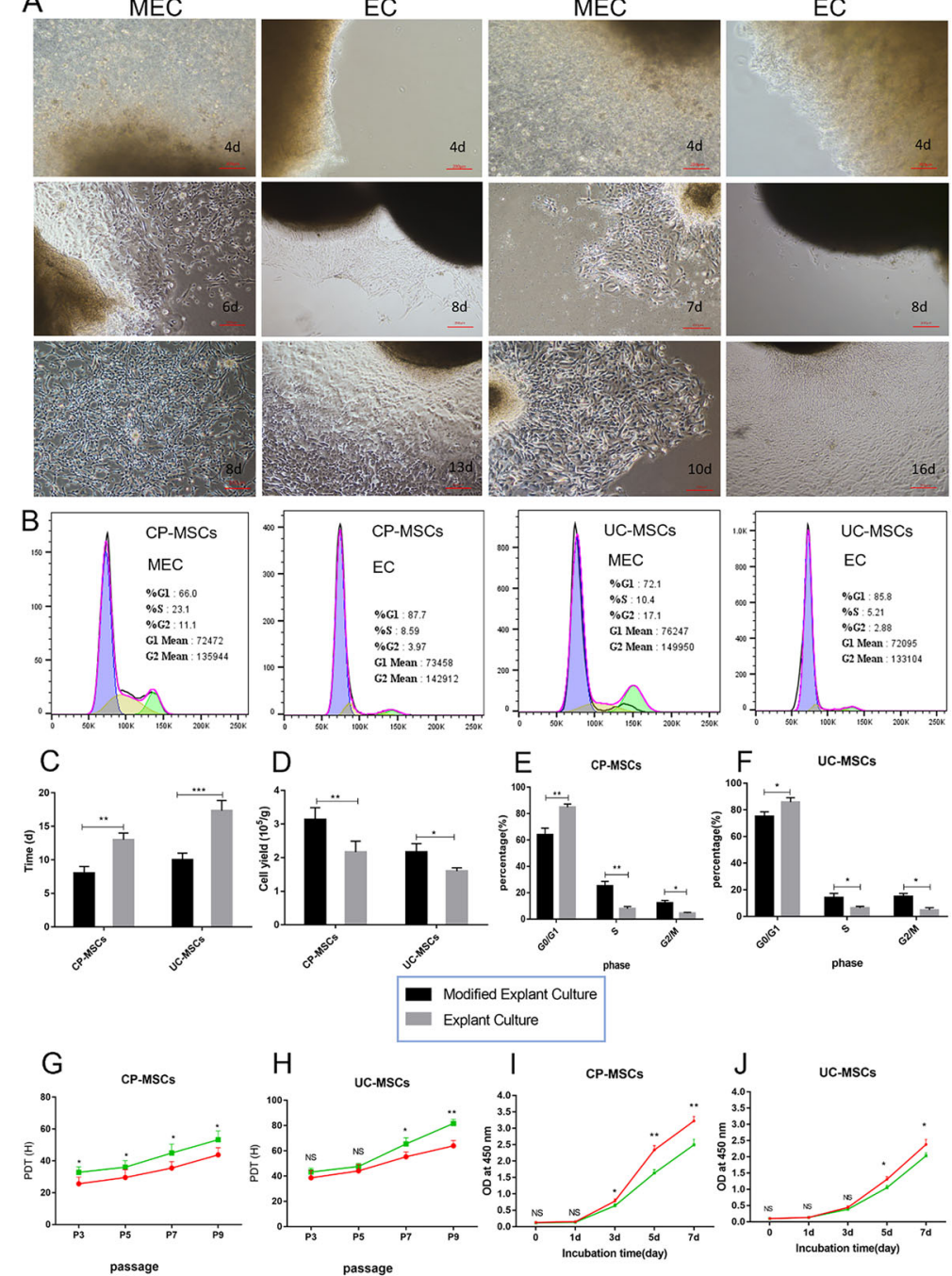

$\rightarrow$ Modified Explant Culture

-- Explant Culture

Fig. 2 The MEC method is superior to the EC method in terms of efficiency and proliferative properties. a Representative diagrams of CP-MSCS and UC-MSCs during MEC and EC (100-fold magnification). $\mathbf{b}$ Cell cycle diagram of MSCs obtained by MEC and EC. $\mathbf{c}$ The mean time to the first passage of CP-MSCs and UC-MSCs in the MEC and EC groups. $\mathbf{d}$ The mean cell yield for the first passage of CP-MSCS and UC-MSCs in the MEC and EC groups. Statistical charts of cell cycle analysis of CP-MSCs (e) and UC-MSCs (f) obtained by MEC and EC (N=3, P4). PDT of CP-MSCS (g) and UC-MSCs (h) obtained by MEC and EC $(N=3, n=3)$. CCK-8 assay of CP-MSCs (i) and UC-MSCs (j) obtained by MEC and EC $(N=3, n=6, P 4)$. All data are expressed as the means $\pm \mathrm{SD}\left({ }^{*} p<0.05,{ }^{* *} p<0.01,{ }^{* * *} p<0.001, \mathrm{NS}\right.$, no significant). MEC, modified explant culture; EC, explant culture; PDT, population doubling time

increase of culture passage. These results suggest that CP-MSCs are superior to other P-MSCs in the origins and that the serum-free culture system we use is more suitable for the proliferation of fetal-derived MSCs.

\section{CP-MSCs show higher proliferation ability}

As shown in Fig. 5, CP-MSCs, CV-MSCs, D-MSCs, and UC-MSCs from the same donor showed different proliferative capacities at the same culture passage. The PDT of CP-MSCs was significantly shorter than that of the other three MSCs, and PDT of all MSCs gradually prolonged with the increase of culture passage (Fig. 5c). The data indicated that CP-MSCs proliferated the fastest, followed by UC-MSCs, and CV-MSCs and DC-MSCs with similar proliferation ability. To further confirm that CP-MSCs have greater proliferative capacity, all MSCs were then seeded at the same quantity for the CCK-8 assay. The viable cell quantity among them was almost the same at day 1 , but started to be significantly different from day 3 (Fig. $5 \mathrm{~d}$ ). The tendency of the growth curve 


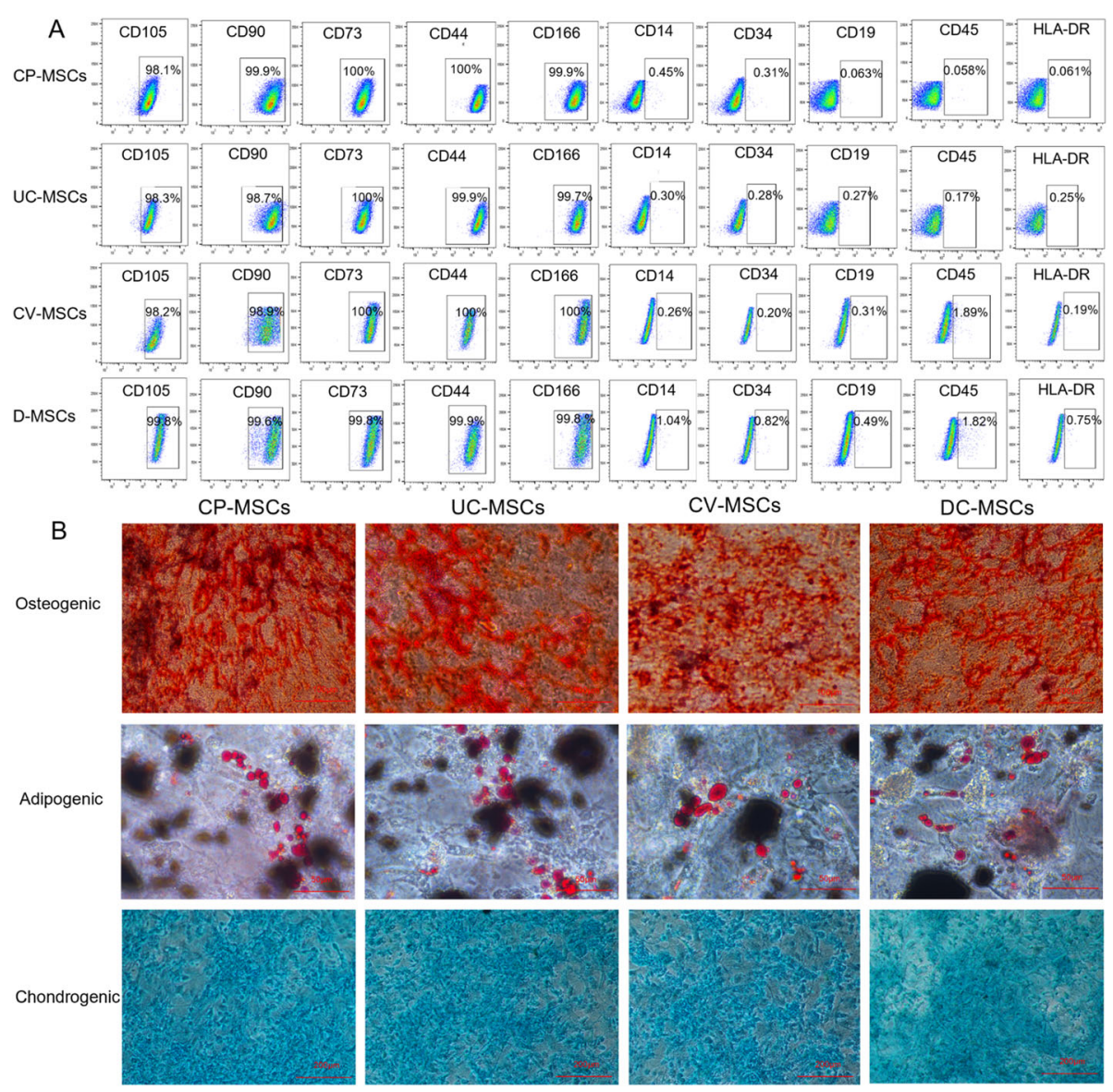

Fig. 3 MSCs obtained by MEC meet the criteria of MSCs proposed by the ISCT. a Cell surface markers of MSCS ( $N=3$, P3) were analyzed by flow cytometry. All MSCs were positive for CD105, CD90, CD73, CD44, and CD166 ( $\geq 95 \%)$ and negative for CD14, CD34, CD19, CD45, and HLA-DR ( $\leq$ 2\%). b Trilineage differentiation of all MSCS (P3)

also verified that CP-MSCs possessed higher proliferation ability. The cell cycles of all MSCs from the three donors were assessed at passage 4. Cell cycle analysis shows that CP-MSCs have more cells in the dividing phase than the other three MSCs (Fig. 5a, b).

\section{CP-MSCs highly express CD106}

Some studies have shown that CD106 and CD54 are involved in MSC-mediated immunomodulation [27], and $\mathrm{CD} 106^{+} \mathrm{MSC}$ have stronger immunomodulatory capacity

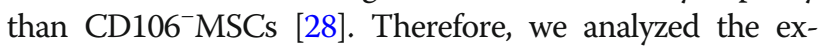
pression of CD106 and CD54 on the surface of these four MSCs. The results showed that CP-MSCs highly expressed CD106 (Fig. 5e, f). The expression of CD54 in MSCs appeared to be opposite to that of CD106. CP-MSCs with high expression of CD106 had low expression of CD54, whereas UC-MSCs with low expression of CD106 highly expressed CD54 (Fig. 5e-g). In addition, we also found that MSCs obtained by the MEC method have higher expression of CD106 than MSCs obtained by EC (Fig. 5e, h).

\section{CP-MSCs show stronger migration ability}

To compare the migration ability of MSCs, all MSCs were subjected to scratch test and transwell migration assay. First, we evaluate MSC migration capacity by introducing scratch test to assess healing area/wounded area ratio at 6 $\mathrm{h}, 12 \mathrm{~h}$, and $24 \mathrm{~h}$. The figure (Fig. 6b, d) showed that the healing area/injured area ratio of CP-MSCs was higher than that of the other three MSCs. Second, we further compared the migration ability of MSCs by transwell migration assay and crystal violet staining to count the number of migrated cells after $6 \mathrm{~h}$ and $12 \mathrm{~h}$ of MSC inoculation. The results (Fig. 6a, c) illustrated that the number of migrated cells in the CP-MSC group was significantly higher than that of the other three groups. In the transwell migration assay, we observed that almost all cells penetrated the filter membrane when MSCs were inoculated for $24 \mathrm{~h}$, and some of the cells had grown on the well plates. Since it was difficult to count the number of migrated cells, we did not evaluate their migration ability in the 24-h group. The above results revealed that CPMSCs possess stronger migration capabilities. 


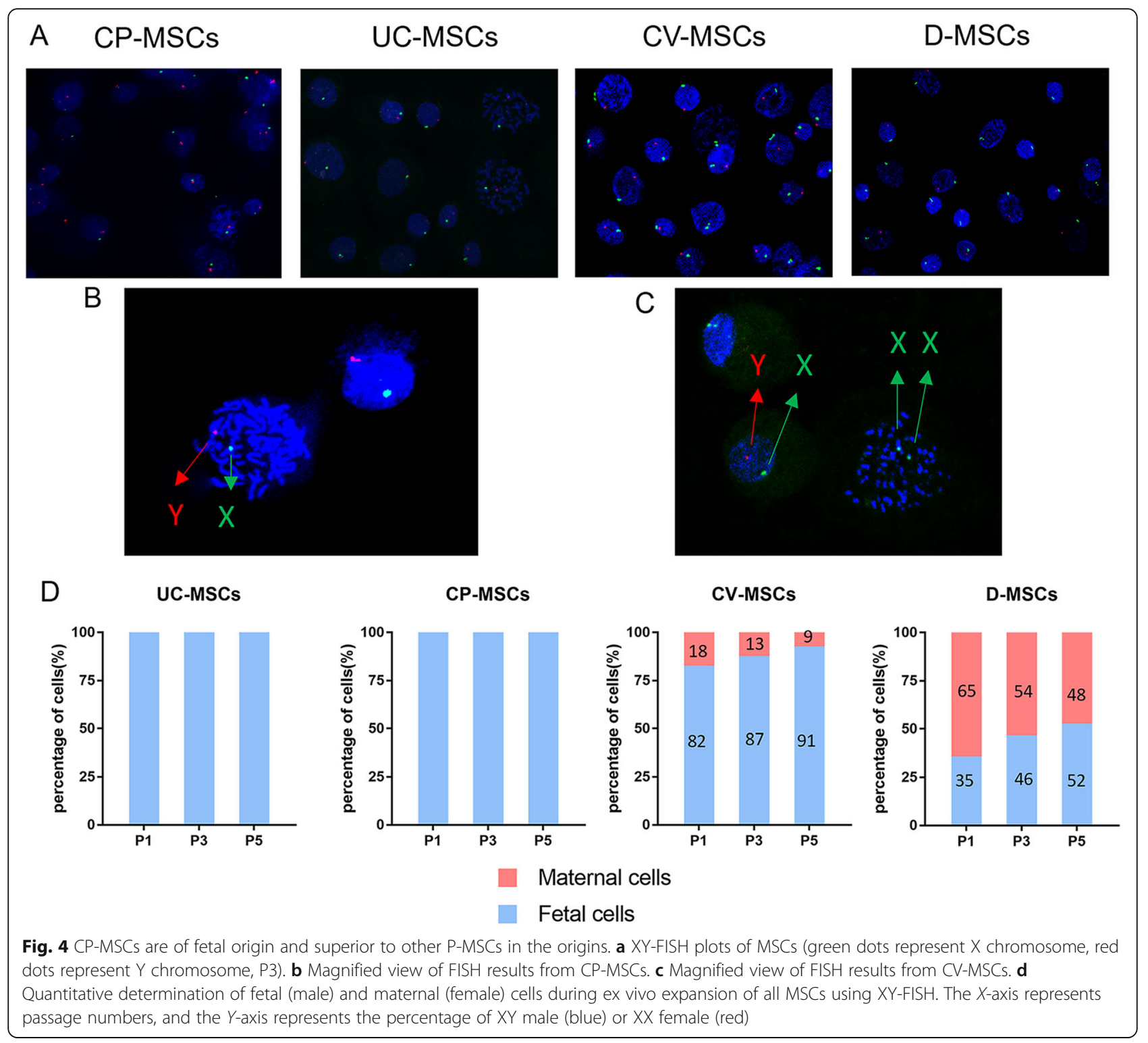

\section{CP-MSCs show greater ability to regulate macrophage from} $M 1$ to $M 2$

We have found that CP-MSCs highly express CD106 compared to the other three MSCs, and a study has reported that $\mathrm{CD} 106^{+} \mathrm{MSC}$ exhibit stronger immunomodulatory capacity than $\mathrm{CD} 106^{-} \mathrm{MSCs}$. In order to compare the immunomodulatory ability of MSCs from different regions of the placenta to macrophage polarization, we cocultured MSCs with macrophages via transwell chamber.

Flow cytometry analysis revealed that only a few cells expressed CD86 and CD163 in macrophages that were not stimulated by LPS. After LPS stimulation, the number of cells expressing CD86 was significantly increased, and the number of cells expressing CD163 was decreased. However, after co-culture with MSCs, the number of cells expressing CD86 was significantly decrease, while the number of cells expressing CD163 increased significantly. After co-culture with MSCs, CD68 ${ }^{+} \mathrm{CD} 86^{+}$ macrophages in the CP-MSC group were lower than other three groups, while $\mathrm{CD} 68^{+} \mathrm{CD} 163^{+}$macrophages in the CP-MSC group were higher than other three groups (Fig. 7a-c). Flow cytometry analysis preliminary showed that CP-MSCs showed stronger immunomodulatory ability than UC-MSCs, CV-MSCs, and D-MSCs.

ELISA was used to determine the concentration of inflammatory factors in the cell culture supernatant. The concentration of TNF- $\alpha$ significantly increased after LPS of administration, whereas that dramatically decreased after co-culture with MSCs. Moreover, the concentration of TNF- $\alpha$ was the lowest in the CP-MSC group. The concentration of IL-10 slightly increased after LPS intervention, while that remarkably increased after co-culture 

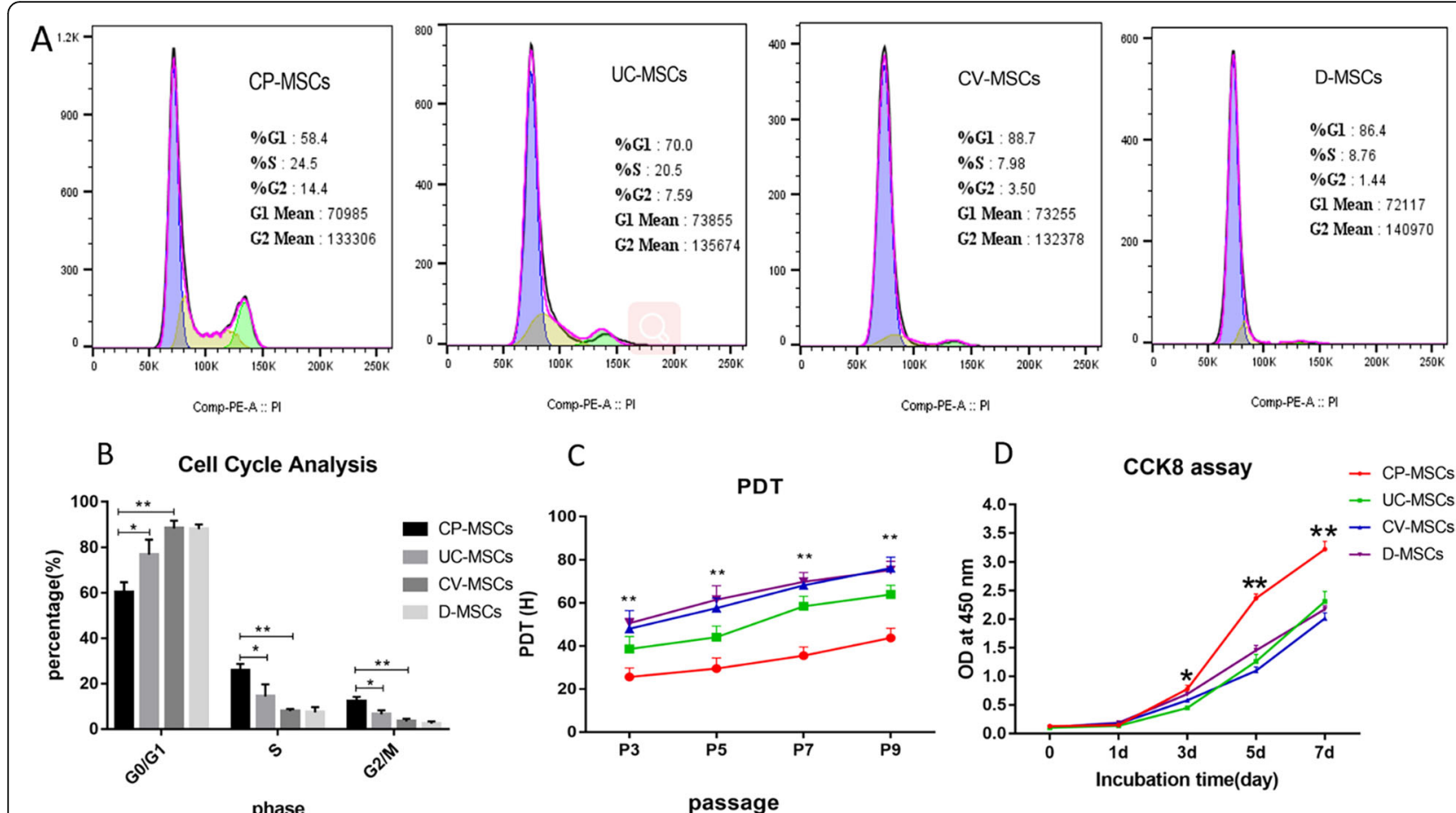

C
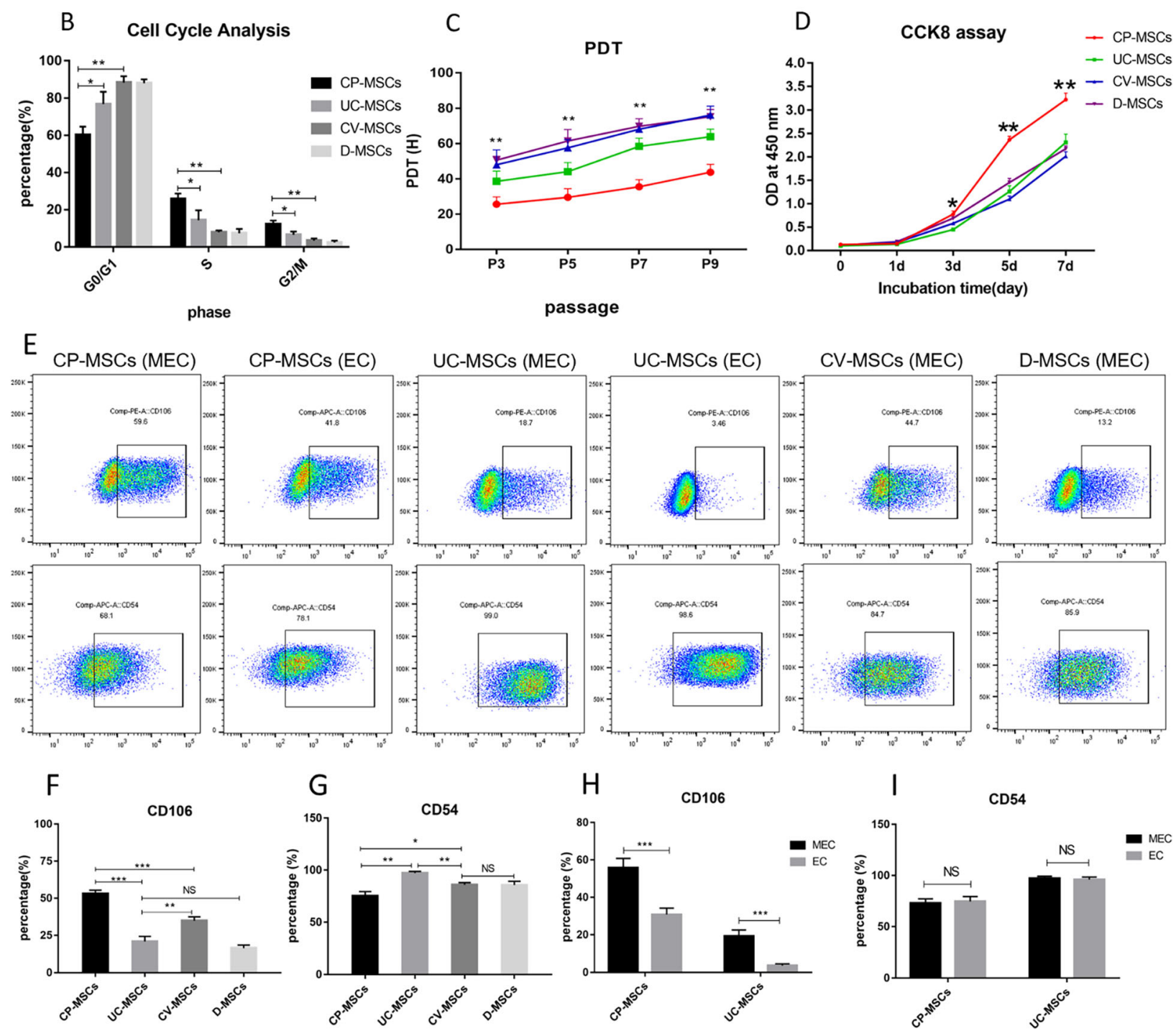

Fig. 5 CP-MSCs showed higher proliferation ability. a Cell cycle diagram of MSCs. b Statistical charts of cell cycle of MSCS. c The PDT of MSCs. $\mathbf{d}$ Growth curves of MSCs. e FSC-H profiles of typical MSCs. $\mathbf{f}$ Statistic analysis of CD106 expression in different MSCs. $\mathbf{g}$ Statistic analysis of CD54 expression in different MSCs. CD106 (h) and CD54 (i) of CP-MSCs and UC-MSCs obtained by MEC and EC. All data are expressed as the means \pm SD $\left(N=3 ;{ }^{*} p<0.05,{ }^{* *} p<0.01,{ }^{* * *} p<0.001, N S\right.$, no significant $)$ 

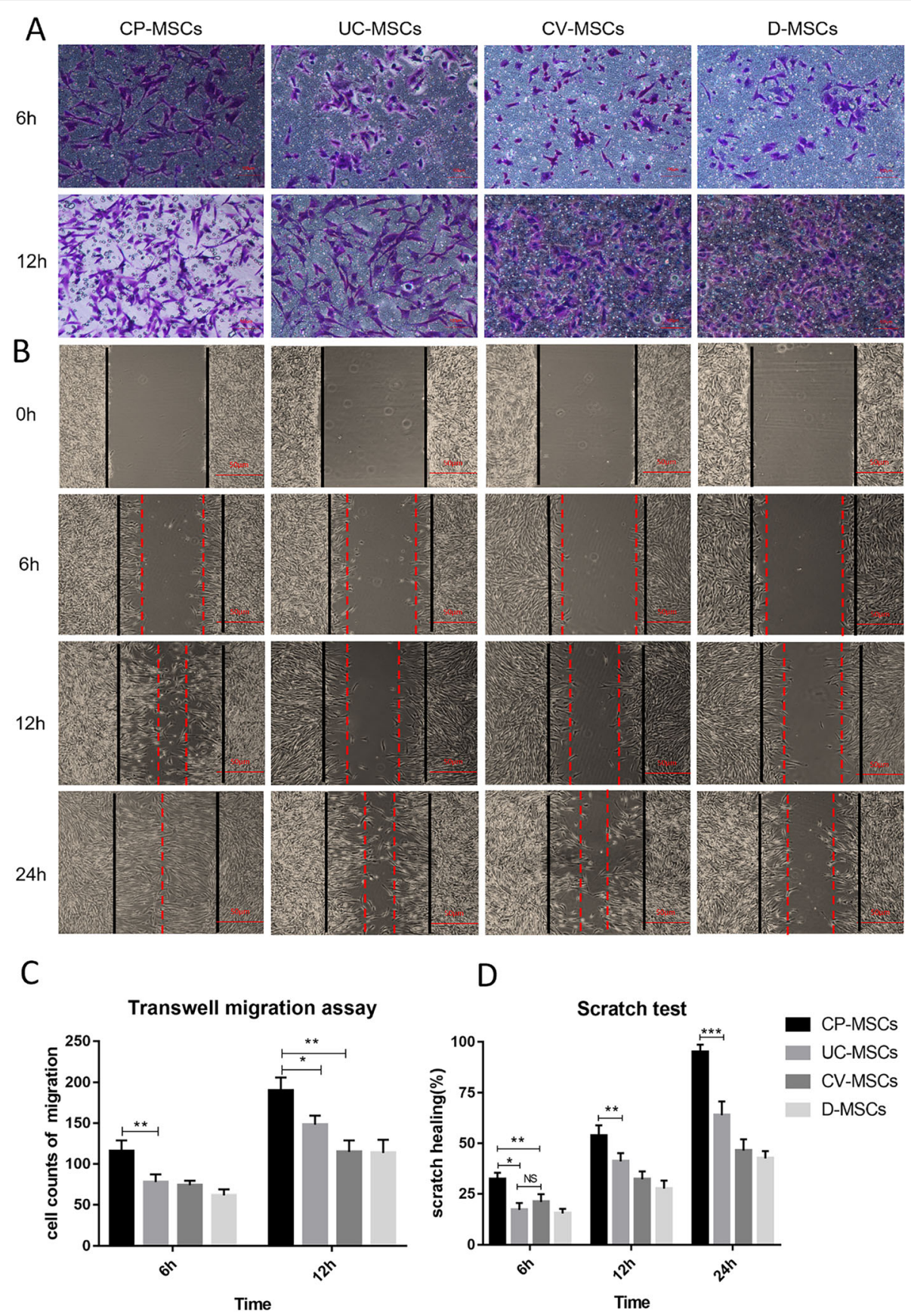

D

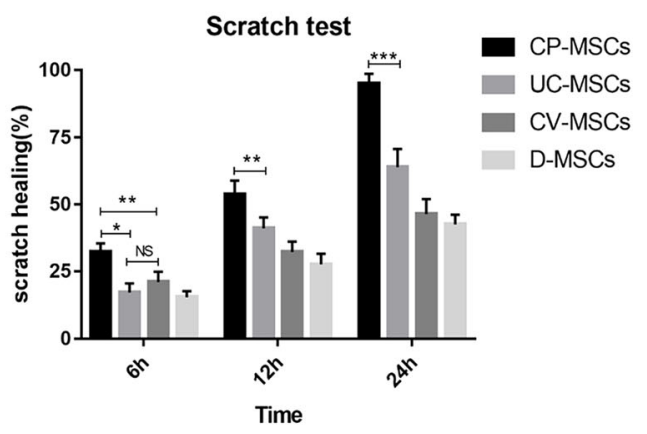

Fig. 6 CP-MSCs show stronger migration capability. a Representative images of MSC transwell migration assay at $6 \mathrm{~h}$ and $12 \mathrm{~h}$ (200-fold magnification). b Representative figures of MSC scratch test at $0 \mathrm{~h}, 6 \mathrm{~h}, 12 \mathrm{~h}$, and $24 \mathrm{~h}$ (the black line indicates the scratch width at $0 \mathrm{~h}$, and the red dotted line indicates the scratch width at each time point, 40-fold magnification). c Cell counts of transwell migration at $6 \mathrm{~h}$ and $12 \mathrm{~h}$. $\mathbf{d}$ Healing area/wounded area ratio in scratch test analysis at $6 \mathrm{~h}, 12 \mathrm{~h}$, and $24 \mathrm{~h}$. All data are expressed as the means $\pm \operatorname{SD}\left(N=3,{ }^{*} p<0.05,{ }^{* *} p<0.01\right.$, ${ }^{* * *} p<0.001$, NS, no significant)

with MSCs. In contrast, IL-10 was the richest in the CPMSC group (Fig. 7d, e).

To further confirm that CP-MSCs exhibit stronger immunomodulatory capacity in regulating macrophage polarization, the expression of major M1 markers (IL-
$1 \beta$, TNF- $\alpha$, inducible nitric oxide synthase (iNOS), and IL-6) and M2 markers (IL-10, arginase (Arg)-1, CD163, and CD206) were evaluated using qRT-PCR. As shown in Fig. $7 \mathrm{f}-\mathrm{m}$, the results indicated that after macrophage stimulation by LPS, the gene expression of M1 


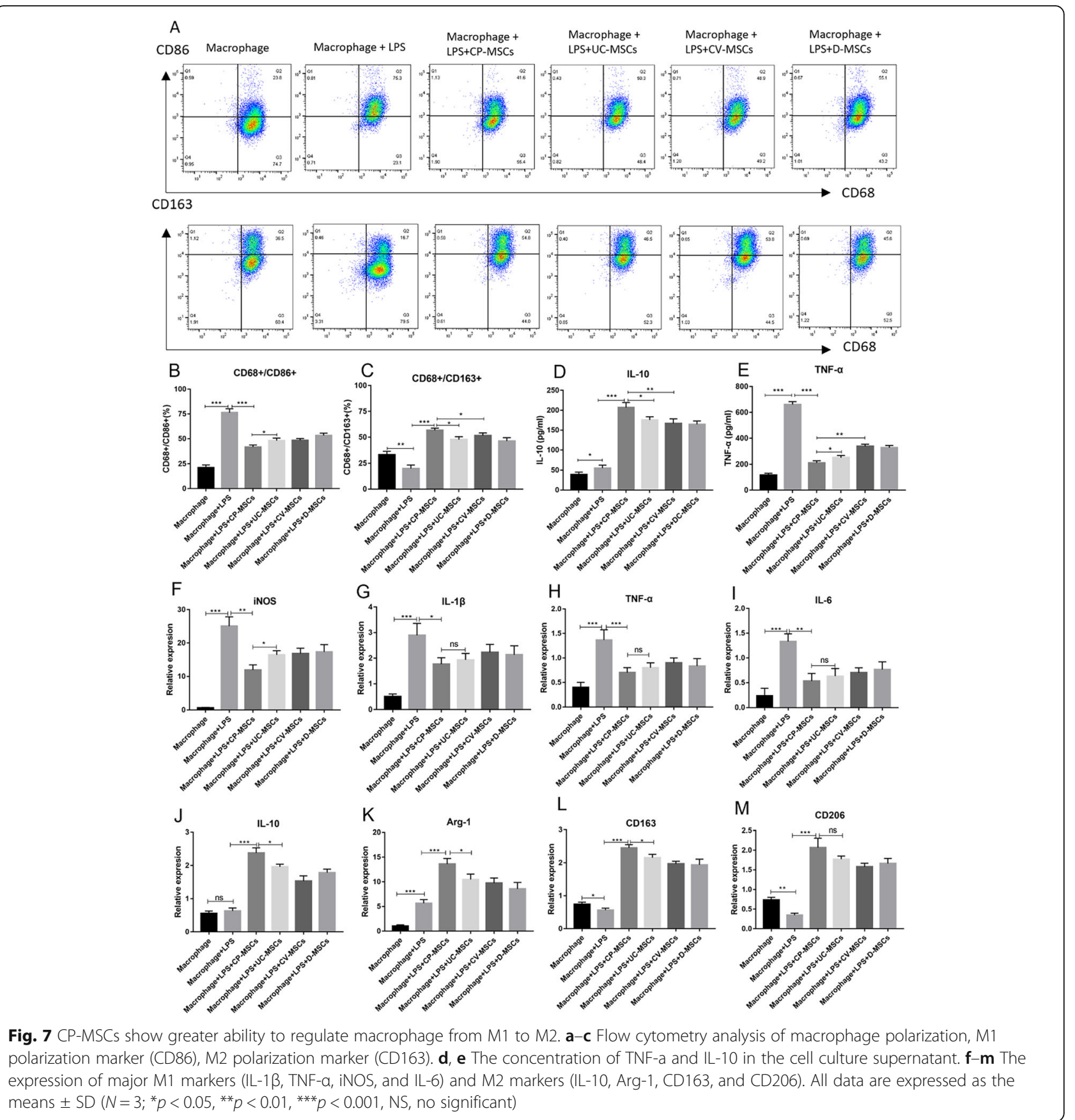

marker was significantly increased, and the gene expression of CD163 and CD206 were significantly decreased, while the gene expression of Arg-1 was significantly elevated. However, after co-culture with MSCs, the gene expression of the M1 marker was significantly lower than that of the LPS group, while the gene expression of the M2 marker was significantly increased, and CP-MSCs show greater immunomodulatory capacity compared with the other three MSCs. Taken together, these results suggest CP-MSCs exhibit stronger ability to regulate macrophage polarization.

\section{Discussion}

In the present study, we developed an efficient and highyield technique to produce high-quality MSCs from the placenta, which is suitable for clinical application. For this technique, the MEC method, serum-free culture system, and the selection of the $\mathrm{CP}$ are critical requirements for successfully generating large numbers of pure fetal PMSCs. The important findings of this study are as follows: (i) The MEC method achieves higher cell yield and shorter time in primary cell confluence in SFM. The harvested 
cells are found to show stronger proliferation ability. (ii) The serum-free culture system we used is more suitable for fetal cell growth and has enrichment effect on fetal MSCs; and (iii) CP seems to be preferable to the tissueharvesting site for generating high-quality MSCs. These CP-MSCs exhibit superior properties in proliferation, migration, and immunomodulatory properties, maintaining the fetal origin over serial passages.

Choosing a suitable isolation method is a vital step in generating P-MSCs with optimal quality and high yield to meet the clinical demand. To date, there are two main methods for isolating P-MSCs including the enzymatic method and the EC method. However, there are some problems regarding the two methods. Enzymatic methods are reported to affect the biological characteristics of MSCs such as proliferative capacity $[19,20]$. In addition, enzymatic methods are more complicated, and the operation process will take more time and money. On the other hand, the EC method requires a longer time for obtaining cells in primary culture than enzymatic methods, which is due to the slower rate of migration of cells from the tissue block. To overcome the above limitations, we developed the MEC method for isolation and culture of P-MSCs by combining an initial mild enzymatic reaction with the subsequent explant culture. The obtained MSCs by MEC possessed MSC characteristics and had stronger proliferation ability than those with the EC method. Notably, the MEC method was found to have the following advantages over the EC method: (i) cells can migrate out of the tissue block in a shorter time; (ii) the cell yield is higher and more MSCs can be obtained in a shorter time; and (iii) MSCs show stronger proliferative activity. These results confirm that the MEC method can shorten the primary confluence time and generate large numbers of P-MSCs, indicating the MEC method is an effective and high-yield technique to isolate P-MSCs from the placenta.

In addition to large quantities of MSCs, as required for clinical therapies, optimal quality is another crucial factor. A series of studies showed that fetalderived MSCs isolated from the placenta have stronger proliferation and differentiation ability, immune regulation, angiogenesis, and migration ability than maternal-derived MSCs $[13,17,29,30]$. Thus, researchers are trying to obtain the pure fetal P-MSCs for clinical applications. However, maternal cell contamination remains a genuine problem during P-MSC isolation and culture. For this reason, the variation in MSCs obtained from different regions of the placenta is one key determinant. Considering the completely fetal origin of $\mathrm{CP}$ tissues [21], we thus selected $\mathrm{CP}$ as the tissue-harvesting site for generating optimal quality of P-
MSC. As evidenced by XY-FISH experiments, our results showed CP-MSCs (P1-P5) were absent of maternal cells, indicating that the obtained CP-MSCs are pure fetal cells without maternal cell contamination. Thus, the specific selection of $\mathrm{CP}$ is one key requirement for the successful isolation and expansion of pure fetal P-MSCs.

For generating pure fetal P-MSCs, the serum-free culture system is another critical requirement. To date, PMSCs that are almost isolated and expanded in the serum-containing medium (SCM) are reported to appear less and less of fetal cells with the prolongation of culture time even though there is a large number of fetal cells in the early stage $[16,18,21]$. Given the complex and unclear composition, SCM might bring various uncertainties to the results of MSC therapy, thereby hindering the large-scale clinical use of MSCs [1, 31]. In this study, we used SFM to isolate and culture MSCs, which has no serum and no animal source components, and clear chemical components. Our result demonstrated that P-MSCs exhibited good biological properties in terms of proliferation, differentiation migration, and immunomodulatory properties in SFM culture, suggesting that our used SFM is suitable for the isolation and expansion of MSCs for clinical application. The result is consistent with the previous report illustrating the advantageous properties of MSC cultured in SFM relative to SCM [32, 33]. Additionally, using the SFM, CV-MSCs contained a small number of maternal cells in primary culture, while D-MSCs contained a large number of maternal cells in primary culture. However, we found that maternal cells gradually decreased while fetal cells gradually increased over serial passages. These data suggest that the serum-free culture system is not conducive to the proliferation of maternal MSCs. Overall, our used serum-free culture system is suitable for isolating and expanding pure fetal MSCs for clinical therapy.

Macrophages are plastic cells displaying versatile functional phenotypes that are dependent on microenvironments [34]. M1 macrophages (M1, the classically activated macrophages) and M2 macrophages (M2, the alternatively activated macrophages) have been defined as the two extremes in a spectrum of macrophage functional phenotypes [35]. The former are mainly involved in pro-inflammatory, and phagocytic response that effectively clears pathogens [36], while the latter mainly participates in antiinflammatory response and promotes angiogenesis, tissue repair, and wound healing [37]. Numerous studies have confirmed that MSCs can regulate macrophage polarization from M1 to M2 by secreting prostaglandin E2 (PGE2) [38], TNF- $\alpha$-induced gene/protein 6 (TSG-6) [39], transforming growth factor (TGF) $\beta 3$ [40], thrombospondin-1 (TSP-1) [40], indoleamine 2,3-dioxygenase (IDO) [41], exosomes [42], and extracellular vesicle mitochondrial transfer [43]. In this study, we found that CP-MSCs showed stronger 
immunomodulatory ability in regulating macrophage polarization from M1 to M2 when compared to UC-MSCs and other P-MSCs. These data suggest CP-MSCs may be optimal source for clinical treatment of immune diseases. In addition, our preliminary study found that CP-MSCs highly expressed COX-2, while PGE-2 in CP-MSC culture supernatant was higher than that of the other three MSCs (Additional file 1: Figure S2). However, the detailed mechanism by which CP-MSCs exhibit stronger immunomodulatory ability than the other three MSCs is still unclear, and more work are needed to be done in our future study.

CD106, known as vascular cell adhesion molecule-1 (VCAM-1), is extensively expressed on endothelial cells and is also constitutively expressed on some stromal cells. Recently, some studies have found that CD106 is expressed in a fraction of MSCs, varying from 30 to $75 \%$ in human BM-MSCs and P-MSCs, and lower expression in UC-MSC and adipose tissue-derived MSCs (AT-MSC) $[23,25,44]$. Cell-cell adhesion mediated by CD106 is critical for $\mathrm{T}$ cell activation and leukocyte recruitment to the inflammation site and, therefore, plays an important role in evoking effective immune responses. Ren et al. showed that CD106 plays an important role in MSC-mediated immunosuppression [27]. Yang and colleagues demonstrated that $\mathrm{CD} 106^{+} \mathrm{MSCs}$ have stronger immunomodulatory ability than $\mathrm{CD} 106^{-} \mathrm{MSCs}$ [28]. In this study, we found that CP-MSCs highly expressed CD106 compared to UC-MSCs, CV-MSCs, and D-MSCs. This result is consistent with our above finding that CP-MSCs have better immunomodulatory effect on M2 macrophage polarization.

Additionally, a series of studies have shown that MSCs can regulate the activation of various immune cells by secreting various cytokines (such as PGE2, IDO, HGF, NO, and exosomes), including T lymphocytes, B lymphocytes, dendritic cells, natural killing cells, and macrophages [3]. Hence, MSCs have been widely used in the therapeutic research of some immune diseases. Interestingly, MSCs have shown to be of crucial importance for the pregnancy and reception of the embryo. It is reported that bone mesenchymal stem cells improve pregnancy outcome by inducing maternal tolerance to the allogeneic fetus in abortionprone matings in mouse [45]. Another study shows that MSCs have a therapeutic effect in an immunebased mouse model of recurrent spontaneous abortion, which may be relevant in the decidual mechanisms of maternal-fetal immune tolerance [46]. Both studies indicate MSCs possess the ability to improve maternal-fetal immune tolerance. However, whether CP-MSCs are involved in the modulation of maternal-fetal immune tolerance is not known, and we will focus on this issue in the future.

\section{Conclusion}

In conclusion, our study developed an efficient and highyield technique to produce high-quality MSCs from the placenta. Moreover, our results presented that the harvested $\mathrm{CP}-\mathrm{MSCs}$ exhibit superior proliferative, migration, and immunomodulatory properties, hence serving as an optimal source of MSCs for clinical application.

\section{Supplementary information}

Supplementary information accompanies this paper at https://doi.org/10. 1186/s13287-019-1405-8.

Additional file 1: Table S1. Primer used for real-time quantitative PCR. Table S2. Immunophenotyping of cells derived from various sources by flow cytometry. Figure S1. Growth status of MSCs derived from different regions of the umbilical cord and placenta. Figure S2. COX-2 and PGE2 of MSCs from different tissues. Figure S3. CP-MSCs are the best choice for P-MSCs isolation. (DOCX $1182 \mathrm{~kb}$ )

\section{Abbreviations}

AM: Amniotic membrane; ANOVA: Analysis of variance; APC: Allophycocyanin; Arg-1: Arginase-1; AT-MSCs: Adipose tissue-derived MSCs; BM: Bone marrow; CCK-8: Cell Counting Kit-8; CP: Chorionic plate; CPMSCs: Chorionic plate-derived MSCs; CV: Chorionic villi; CV-MSCs: Chorionic villi-derived MSCs; D: Decidua; DMEM: Dulbecco's modified Eagle medium; D-MSCs: Decidua-derived MSCs; EC: Explant culture; ELISA: Enzyme-linked immunosorbent assay; FISH: Fluorescence in situ hybridization;

FITC: Fluorescein isothiocyanate; GVHD: Graft versus host disease; IDO: Indoleamine 2,3-dioxygenase; IL: Interleukin; iNOS: Inducible nitric oxide synthase; ISCT: International Society for Cellular Therapies;

LPS: Lipopolysaccharide; MEC: Modified explant culture; MSCs: Mesenchymal stem cells; P: Placenta; PBS: Phosphate-buffered saline; PDT: Population doubling time; PE: Phycoerythrin; PGE2: Prostaglandin E2; P-MSCs: Placentaderived MSCS; SCM: Serum-containing medium; SDF-1: Stromal-derived factor-1; SFM: Serum-free medium; TGF: Transforming growth factor; TNFa: Tumor necrosis factor-a; TSG-6: TNF-a-induced gene/protein 6; TSP1: Thrombospondin-1; UC: Umbilical cord; UC-MSCs: Umbilical cord-derived MSCs; VCAM-1: Vascular cell adhesion molecule-1

\section{Acknowledgements}

We thank Kai-jiong Li for the schematic model assistance. We appreciate the staff and patients of the Department of Obstetrics and Gynecology, The General Hospital of Western Theater Command, for giving us placentae.

\section{Authors' contributions}

$\mathrm{QH}$ and $\mathrm{YY}$ contributed equally to this study. QH and HS conceived and designed the experiments. $\mathrm{QH}$ and $\mathrm{YY}$ performed the majority of the experiments and analyzed the data. CL helped with the isolation of mesenchymal stem cells. SL carried out the isolation and culture of macrophages. YW, RL, and TC helped in performing the analysis with constructive discussions. $\mathrm{QH}$ and $\mathrm{HS}$ drafted the manuscript. LT revised the final version. All authors read and approved the final manuscript.

\section{Funding}

This work was supported by the National Natural Science Foundation of China (NO. 81772001), the National Clinical Key Subject of China (No. 41792113), and the Technology Plan Program of Sichuan Provence (NO. 2015SZ0229, 2016HH0067, 2018JY0041, and 2019YJ0277).

Availability of data and materials

All data generated or analyzed during this study are included in this published article.

Ethics approval and consent to participate

This study was approved by the Institutional Ethics Committee of the General Hospital of Western Theater Command. All samples were obtained from donors with written informed consent. 


\section{Consent for publication}

Not applicable

\section{Competing interests}

The authors declare that they have no competing interests.

\section{Author details}

${ }^{1}$ Department of General Surgery \& Pancreatic Injury and Repair Key Laboratory of Sichuan Province, The General Hospital of Western Theater Command (Chengdu Military General Hospital), Chengdu 610083, China. ${ }^{2}$ College of Medicine, Southwest Jiaotong University, Chengdu 610031, China.

Received: 4 July 2019 Revised: 26 August 2019

Accepted: 2 September 2019 Published online: 17 October 2019

\section{References}

1. Ma J, Wu J, Han L, Jiang X, Yan L, Hao J, Wang H. Comparative analysis of mesenchymal stem cells derived from amniotic membrane, umbilical cord and chorionic plate under serum-free condition. Stem Cell Res Ther. 2019; 10(1):19.

2. Mareschi K, Castiglia S, Sanavio F, Rustichelli D, Muraro M, Defedele D, Bergallo M, Fagioli F. Immunoregulatory effects on T lymphocytes by human mesenchymal stromal cells isolated from bone marrow, amniotic fluid, and placenta. Exp Hematol. 2016;44(2):138-50.e1.

3. Shi Y, Wang Y, Li Q, Liu K, Hou J, Shao C, Wang Y. Immunoregulatory mechanisms of mesenchymal stem and stromal cells in inflammatory diseases. Nat Rev Nephrol. 2018;14(8):493-507.

4. Gao L, Zhang Y, Hu B, Liu J, Kong P, Lou S, Su Y, Yang T, Li H, Liu Y, Zhang C, Gao L, Zhu L, Wen Q, et al. Phase II multicenter, randomized, doubleblind controlled study of efficacy and safety of umbilical cord-derived mesenchymal stromal cells in the prophylaxis of chronic graft-versus-host disease after HLA-haploidentical stem-cell transplantation. J Clin Oncol. 2016;34(24):2843-50

5. Lin BL, Chen JF, Qiu WH, Wang KW, Xie DY, Chen XY, Liu QL, Peng L, Li JG, Me YY, Weng WZ, Peng YW, Cao HJ, Xie JQ, et al. Allogeneic bone marrow-derived mesenchymal stromal cells for hepatitis B virus-related acute-on-chronic liver failure: a randomized controlled trial. Hepatol. 2017;66(1):209-19.

6. Gao LR, Chen Y, Zhang NK, Yang XL, Liu HL, Wang ZG, Yan XY, Wang Y, Zhu ZM, Li TC, Wang LH, Chen HY, Chen YD, Huang CL, et al. Intracoronary infusion of Wharton's jelly-derived mesenchymal stem cells in acute myocardial infarction: double-blind, randomized controlled trial. BMC Med. 2015;13:162.

7. Alvaro-Gracia JM, Jover JA, Garcia-Vicuna R, Carreno L, Alonso A, Marsal S, Blanco F, Martinez-Taboada VM, Taylor P, Martin-Martin C, DelaRosa O, Tagarro I, Diaz-Gonzalez F. Intravenous administration of expanded allogeneic adipose-derived mesenchymal stem cells in refractory rheumatoid arthritis (Cx611): results of a multicentre, dose escalation, randomised, single-blind, placebo-controlled phase $\mathrm{lb} /$ /la clinical trial. Ann Rheum Dis. 2017;76(1):196-202.

8. Suk KT, Yoon JH, Kim MY, Kim CW, Kim JK, Park H, Hwang SG, Kim DJ, Lee BS, Lee SH, Kim HS, Jang JY, Lee CH, Kim BS, et al. Transplantation with autologous bone marrow-derived mesenchymal stem cells for alcoholic cirrhosis: phase 2 trial. Hepatology. 2016;64(6):2185-97.

9. D'Ippolito G, Schiller PC, Ricordi C, Roos BA, Howard GA. Age-related osteogenic potential of mesenchymal stromal stem cells from human vertebral bone marrow. J Bone Miner Res. 1999;14(7):1115-22.

10. Mueller SM, Glowacki J. Age-related decline in the osteogenic potential of human bone marrow cells cultured in three-dimensional collagen sponges. J Cell Biochem. 2001;82(4):583-90.

11. Ganguly P, El-Jawhari JJ, Giannoudis PV, Burska AN, Ponchel F, Jones EA. Age-related changes in bone marrow mesenchymal stromal cells: a potential impact on osteoporosis and osteoarthritis development. Cell Transplant. 2017;26(9):1520-9.

12. Batsali AK, Pontikoglou C, Koutroulakis D, Pavlaki KI, Damianaki A, Mavroud I, Alpantaki K, Kouvidi E, Kontakis G, Papadaki HA. Differential expression of cell cycle and WNT pathway-related genes accounts for differences in the growth and differentiation potential of Wharton's jelly and bone marrowderived mesenchymal stem cells. Stem Cell Res Ther. 2017;8(1):102.

13. Zhu Y, Yang Y, Zhang Y, Hao G, Liu T, Wang L, Yang T, Wang Q, Zhang G, Wei J, Li Y. Placental mesenchymal stem cells of fetal and maternal origins demonstrate different therapeutic potentials. Stem Cell Res Ther. 2014;5(2):48.
14. Deuse T, Stubbendorff M, Tang-Quan K, Phillips N, Kay MA, Eiermann T, Phan TT, Volk HD, Reichenspurner H, Robbins RC, Schrepfer S. Immunogenicity and immunomodulatory properties of umbilical cord lining mesenchymal stem cells. Cell Transplant. 2011;20(5):655-67.

15. Talwadekar MD, Kale VP, Limaye LS. Placenta-derived mesenchymal stem cells possess better immunoregulatory properties compared to their cordderived counterparts-a paired sample study. Sci Rep. 2015;5:15784.

16. Pelekanos RA, Sardesai VS, Futrega K, Lott WB, Kuhn M, Doran MR. Isolation and expansion of mesenchymal stem/stromal cells derived from human placenta tissue. J Visualized Exp. 2016;112:e54204.

17. Mathews S, Lakshmi Rao K, Suma Prasad K, Kanakavalli MK, Govardhana Reddy A, Avinash Raj T, Thangaraj K, Pande G. Propagation of pure fetal and maternal mesenchymal stromal cells from terminal chorionic villi of human term placenta. Sci Rep. 2015;5:10054.

18. Heazlewood CF, Sherrell H, Ryan J, Atkinson K, Wells CA, Fisk NM. High incidence of contaminating maternal cell overgrowth in human placental mesenchymal stem/stromal cell cultures: a systematic review. Stem Cells Transl Med. 2014;3(11):1305-11.

19. Salehinejad $P$, Alitheen NB, Ali AM, Omar AR, Mohit M, Janzamin E, Samani FS, Torshizi Z, Nematollahi-Mahani SN. Comparison of different methods for the isolation of mesenchymal stem cells from human umbilical cord Wharton's jelly. In Vitro Cell Dev Biol Anim. 2012;48(2):75-83.

20. Yoon JH, Roh EY, Shin S, Jung NH, Song EY, Chang JY, Kim BJ, Jeon HW. Comparison of explant-derived and enzymatic digestion-derived MSCs and the growth factors from Wharton's jelly. Biomed Res Int. 2013;2013:428726.

21. Beeravolu N, McKee C, Alamri A, Mikhael S, Brown C, Perez-Cruet M, Chaudhry GR. Isolation and characterization of mesenchymal stromal cells from human umbilical cord and fetal placenta. J Visualized Exp. 2017;122.

22. Sardesai VS, Shafiee A, Fisk NM, Pelekanos RA. Avoidance of maternal cell contamination and overgrowth in isolating fetal chorionic villi mesenchymal stem cells from human term placenta. Stem Cells Transl Med. 2017;6(4):1070-84.

23. Ventura Ferreira MS, Bienert M, Muller K, Rath B, Goecke T, Oplander C, Braunschweig T, Mela P, Brummendorf TH, Beier F, Neuss S. Comprehensive characterization of chorionic villi-derived mesenchymal stromal cells from human placenta. Stem Cell Res Ther. 2018;9(1):28.

24. Wang C, Yu X, Cao Q, Wang Y, Zheng G, Tan TK, Zhao H, Zhao Y, Wang Y, Harris D. Characterization of murine macrophages from bone marrow, spleen and peritoneum. BMC Immunol. 2013;14:6.

25. Wu M, Zhang R, Zou Q, Chen Y, Zhou M, Li X, Ran R, Chen Q. Comparison of the biological characteristics of mesenchymal stem cells derived from the human placenta and umbilical cord. Sci Rep. 2018;8(1):5014.

26. Dominici M, Le Blanc K, Mueller I, Slaper-Cortenbach I, Marini F, Krause D, Deans R, Keating A, Prockop D, Horwitz E. Minimal criteria for defining multipotent mesenchymal stromal cells. The International Society for Cellular Therapy position statement. Cytotherapy. 2006;8(4):315-7.

27. Ren G, Zhao X, Zhang L, Zhang J, L'Huillier A, Ling W, Roberts Al, Le AD, Shi S, Shao C, Shi Y. Inflammatory cytokine-induced intercellular adhesion molecule-1 and vascular cell adhesion molecule-1 in mesenchymal stem cells are critical for immunosuppression. J Immunol. 2010;184(5):2321-8.

28. Yang ZX, Han ZB, Ji YR, Wang YW, Liang L, Chi Y, Yang SG, Li LN, Luo WF, Li JP, Chen DD, Du WJ, Cao XC, Zhuo GS, et al. CD106 identifies a subpopulation of mesenchymal stem cells with unique immunomodulatory properties. PLoS One. 2013;8(3):e59354.

29. Araujo AB, Salton GD, Furlan JM, Schneider N, Angeli MH, Laureano AM, Silla L, Passos EP, Paz AH. Comparison of human mesenchymal stromal cells from four neonatal tissues: amniotic membrane, chorionic membrane, placental decidua and umbilical cord. Cytotherapy. 2017;19(5):577-85.

30. Gonzalez PL, Carvajal C, Cuenca J, Alcayaga-Miranda F, Figueroa FE, Bartolucci J, Salazar-Aravena L, Khoury M. Chorion mesenchymal stem cells show superior differentiation, immunosuppressive, and angiogenic potentials in comparison with haploidentical maternal placental cells. Stem Cells Transl Med. 2015;4(10):1109-21.

31. Sundin M, Ringden O, Sundberg B, Nava S, Gotherstrom C, Le Blanc K. No alloantibodies against mesenchymal stromal cells, but presence of anti-fetal calf serum antibodies, after transplantation in allogeneic hematopoietic stem cell recipients. Haematologica. 2007;92(9):1208-15.

32. Wang $Y$, Wu H, Yang Z, Chi Y, Meng L, Mao A, Yan S, Hu S, Zhang J, Zhang Y, Yu W, Ma Y, Li T, Cheng Y, et al. Human mesenchymal stem cells possess different biological characteristics but do not change their therapeutic potential when cultured in serum free medium. Stem Cell Res Ther. 2014; 5(6):132. 
33. Lee MS, Youn C, Kim JH, Park BJ, Ahn J, Hong S, Kim YD, Shin YK, Park SG. Enhanced cell growth of adipocyte-derived mesenchymal stem cells using chemically-defined serum-free media. Int J Mol Sci. 2017;18(8):1779.

34. Stout RD, Jiang C, Matta B, Tietzel I, Watkins SK, Suttles J. Macrophages sequentially change their functional phenotype in response to changes in microenvironmental influences. J Immunol. 2005;175(1):342-9.

35. Murray PJ. Macrophage polarization. Annu Rev Physiol. 2017;79:541-66.

36. Sica A, Mantovani A. Macrophage plasticity and polarization: in vivo veritas. J Clin Invest. 2012;122(3):787-95.

37. Martinez FO, Helming L, Gordon S. Alternative activation of macrophages: an immunologic functional perspective. Annu Rev Immunol. 2009;27:451-83.

38. Manferdini C, Paolella F, Gabusi E, Gambari L, Piacentini A, Filardo G, FleuryCappellesso S, Barbero A, Murphy M, Lisignoli G. Adipose stromal cells mediated switching of the pro-inflammatory profile of M1-like macrophages is facilitated by PGE2: in vitro evaluation. Osteoarthr Cartil. 2017:25(7):1161-71.

39. Song WJ, Li Q, Ryu MO, Ahn JO, Ha Bhang D, Chan Jung Y, Youn HY. TSG-6 secreted by human adipose tissue-derived mesenchymal stem cells ameliorates DSS-induced colitis by inducing M2 macrophage polarization in mice. Sci Rep. 2017;7(1):5187.

40. Chen X, Yang B, Tian J, Hong H, Du Y, Li K, Li X, Wang N, Yu X, Wei X. Dental follicle stem cells ameliorate lipopolysaccharide-induced inflammation by secreting TGF-beta3 and TSP-1 to elicit macrophage M2 polarization. Cell Physiol Biochem. 2018;51(5):2290-308.

41. Francois M, Romieu-Mourez R, Li M, Galipeau J. Human MSC suppression correlates with cytokine induction of indoleamine 2,3-dioxygenase and bystander M2 macrophage differentiation. Mol Ther. 2012;20(1):187-95.

42. Li J, Xue H, Li T, Chu X, Xin D, Xiong Y, Qiu W, Gao X, Qian M, Xu J, Wang Z, Li G. Exosomes derived from mesenchymal stem cells attenuate the progression of atherosclerosis in $\mathrm{ApoE}(-/-)$ mice via miR-let7 mediated infiltration and polarization of M2 macrophage. Biochem Biophys Res Commun. 2019:510(4):565-72.

43. Morrison TJ, Jackson MV, Cunningham EK, Kissenpfennig A, McAuley DF, O'Kane CM, Krasnodembskaya AD. Mesenchymal stromal cells modulate macrophages in clinically relevant lung injury models by extracellular vesicle mitochondrial transfer. Am J Respir Crit Care Med. 2017;196(10):1275-86.

44. Mo M, Wang S, Zhou Y, Li H, Wu Y. Mesenchymal stem cell subpopulations: phenotype, property and therapeutic potential. Cell Mol Life Sci. 2016; 73(17):3311-21.

45. Meng YH, Zhu XH, Yan LY, Zhang Y, Jin HY, Xia X, Li R, Qiao J. Bone mesenchymal stem cells improve pregnancy outcome by inducing maternal tolerance to the allogeneic fetus in abortion-prone matings in mouse. Placenta. 2016:47:29-36.

46. Munoz-Fernandez R, De La Mata C, Requena F, Martin F, Fernandez-Rubio P, Llorca T, Ruiz-Magana MJ, Ruiz-Ruiz C, Olivares EG. Human predecidual stromal cells are mesenchymal stromal/stem cells and have a therapeutic effect in an immune-based mouse model of recurrent spontaneous abortion. Stem Cell Res Ther. 2019;10(1):177.

\section{Publisher's Note}

Springer Nature remains neutral with regard to jurisdictional claims in published maps and institutional affiliations.

Ready to submit your research? Choose BMC and benefit from:

- fast, convenient online submission

- thorough peer review by experienced researchers in your field

- rapid publication on acceptance

- support for research data, including large and complex data types

- gold Open Access which fosters wider collaboration and increased citations

- maximum visibility for your research: over $100 \mathrm{M}$ website views per year

At $\mathrm{BMC}$, research is always in progress.

Learn more biomedcentral.com/submissions 